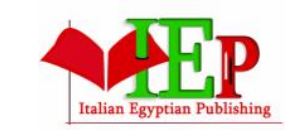

ISSN: $2735-4415$
INTERNATIONAL JOURNAL OF

MULTIDISCIPLINARY STUDIES IN ARCHITECTURE

AND CULTURAL HERITAGE

VOLUME 2, ISSUE 1, 2019, 54-66.

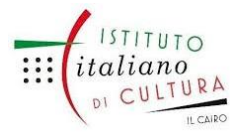

www.egyptfuture.org/ojs/

\title{
The Mutual Relation Between Identity and Cultural Tourism (Reimaging Historic Districts)
}

\author{
Mohamed Atef a, * \\ a Zagazig University, Faculty of Engineering
}

\begin{abstract}
Since the civilizations began, humans have travelled. Food, water, safety or acquisition of resources, through trade, was the early travel goals; but the idea of travel for pleasure or exploration rapidly emerged. Today, tourism has become a collection of activities, services, and industries that deliver a travel experience for individuals or groups that are travelling away from home. Cultural Tourism has been defined as 'the movement of persons to cultural attractions away from their normal places of residence, with the intention to gather new information and experiences to satisfy their cultural needs'. These cultural needs can include the solidification of one's own cultural identity, with respect to cultural diversity. Currently, Cultural Tourism is growing in importance on the national and international levels. It has become an important instrument of knowledge; a tool for accelerating integration and a vehicle of culture. It is considered a factor of economic development on one hand; while on the other hand it's a reflection of a society's needs and circumstances represented through its architectural heritage. In Egypt, Heritage Identity has been affected by different eras through many factors - including political, religious and economic ones - which led to the diversity in the architecture of each period of time over the ages. Therefore, we can say that Egypt enjoys a distinguished cultural heritage, accumulated over thousands of years.

\begin{tabular}{ll}
\hline Keywords & \\
- & Tourism. \\
- & Identity. \\
- & Cultural Heritage. \\
- & Diversity. \\
\hline
\end{tabular}
\end{abstract}

\section{Introduction}

The world as we know it today exists as testimony to, and evidence of, the fact that people travel. Early patterns of travel were fundamentally directed by basic human needs (finding food and shelter), exchange (trade), and relationships with natural phenomena (developing new settlements, escaping droughts or floods etc.) and as a result of conquest and conflict (occupation, expulsion, forced migration and resettlement).

From the late seventeenth and well into the twentieth century, motivations such as curiosity, education and social betterment took over as 'essential' travel evolved into discretionary leisure travel, gradually moving from a pursuit of the social elite of the developed world, to a widespread activity of the masses of the developed world, supported by a highly complex network of support structures and services. ${ }^{\text {i }}$

\section{CULTURAL TOURISM:}

Tourism has becoming an increasingly global and complex phenomenon, with 


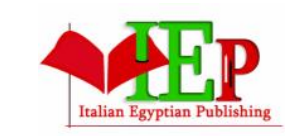

ISSN: $2735-4415$
INTERNATIONAL JOURNAL OF

MULTIDISCIPLINARY STUDIES IN ARCHITECTURE

AND CULTURAL HERITAGE

VOLUME 2, ISSUE 1, 2019, $54-66$.

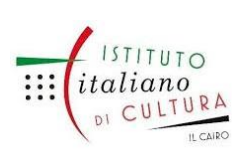

www.egyptfuture.org/ojs/

political, economic, social, cultural, environmental, and educational dimensions. Tourism is considered to be the 'largest of multi-national activities. 'ii

It is a culture, and its practices and structures are very much an extension of the normative cultural framing from which it emerges.

Estimates from the World Tourism Organization (2005) anticipate that by the year 2020 international arrivals are expected to reach over 1.56 billion. This will comprise 1.2 billion intraregional arrivals and 0.4 billion will be long-haul travelers. Europe is scheduled to be the top receiving region with 717 million tourists, followed by East Asia and the Pacific with 397 million, the Americas with 282 million, and Africa, the Middle East and South Asia. Above average growth regions are scheduled to be East Asia and the Pacific, South Asia, the Middle East and Africa. ${ }^{\text {ii }}$

The mutually beneficial relationship between tourism and culture has been one of the major sources of tourism growth in recent decades. As underlined by the OECD's The Impact of Culture on Tourism (2009), this relationship is changing, with the previous emphasis on tangible heritage being supplemented by new forms of tourism based on intangible heritage and contemporary creativity. As destinations seek competitive advantage through creativity and consumers are looking for engaging tourism experiences, economy approaches offer the potential to add value through developing engaging content and experiences, supporting innovation and helping to make places more distinctive and attractive. ${ }^{\text {iv }}$

The expanded role for culture in tourism development mirrored the growth of culture as a factor of development in general, showing how the growth of culture-led development was tied to the workings of the symbolic economy. Culture provided the symbols, such as museums, art galleries and iconic architecture, which could be used to increase land values and stimulate business activity. This growth in turn supported employment in the cultural sector, strengthening its lobbying for more investment in culture. This produced powerful arguments to preserve heritage of the past and expand contemporary culture in order to maximize the 'real cultural capital' of places. Culture has therefore come to play an important role in distinguishing places from each other."

Growth of 'cultural tourism' has been one of the major trends in global tourism in the past three decades and is still seen as one of the major growth areas for the future. ${ }^{\text {vi }}$ Apparent success of culture-led or cultural development strategies has encouraged more cities, regions and nations touse the combination of culture and tourism.

Meanwhile we can say that tourism in Egypt, within a global culture and competitive world economy, is faced with many challenges such as the leakage of tourism revenues and benefits into First World multi-national agencies and enterprises. Yet, tourism in Egypt could also be the driving force for valuable opportunities leading to 'progress' and'development.'As Egypt, which combined an age-old tradition of travel and intercultural exchanges with a heritage of buildings and exceptionally rich and varied living cultures, was a particularly welcome choice for reflection between cultural heritage $\&$ tourism. 


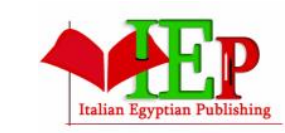

ISSN: $2735-4415$
INTERNATIONAL JOURNAL OF

MULTIDISCIPLINARY STUDIES IN ARCHITECTURE

AND CULTURAL HERITAGE

VOLUME 2, ISSUE 1, 2019, 54-66.

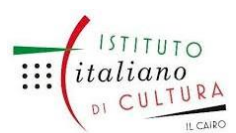

www.egyptfuture.org/ojs/

\section{CULTURAL DIVERSITY:}

Culture, in its widest sense, provides a set of material and symbolic resources that are abundantin supply, and highly mobile. Culture refers to the customs, practices, languages, values and world views that define social groups such as those based on nationality, ethnicity, region or common interests.

In line with the conclusions of the World Conference on Cultural Policies (MONDIACULT, 1982), of the World Commission on Culture and Development (Our Creative Diversity, 1997), of the Intergovernmental Conference on Cultural Policies for Development and of the UNESCO Universal Declaration on Cultural Diversity, "culture should be regarded as the set of distinctive spiritual, material, intellectual and emotional features of society or a social group, and that it encompasses, in addition to art and literature, lifestyles, ways of living together, value systems, traditions and beliefs". vii

Article1 of the UNESCO Universal Declaration on Cultural Diversity stresses that "culture takes diverse forms across time and space. This diversity is embodied in the uniqueness and plurality of the identities of the groups and societies making up humankind. As a source of exchange, innovation and creativity, cultural diversity is as necessary for humankind as biodiversity is for nature. In this sense, it is the common heritage of humanity and should be recognized and affirmed for the benefit of present and future generations". viii

Therefore, it is useful to stress the fact that culture is here to be understood in its widest sense. Indeed, from the outset we have been anxious for culture to be understood as being that which enables human beings to rise above nature or the way in which a people lives in society. The definition is therefore fairly broad, is not restricted to heritage alone and also incorporates the culture of the daily lived experience of whole peoples. ${ }^{\text {ix }}$

Figure (1): Cultural Diversity

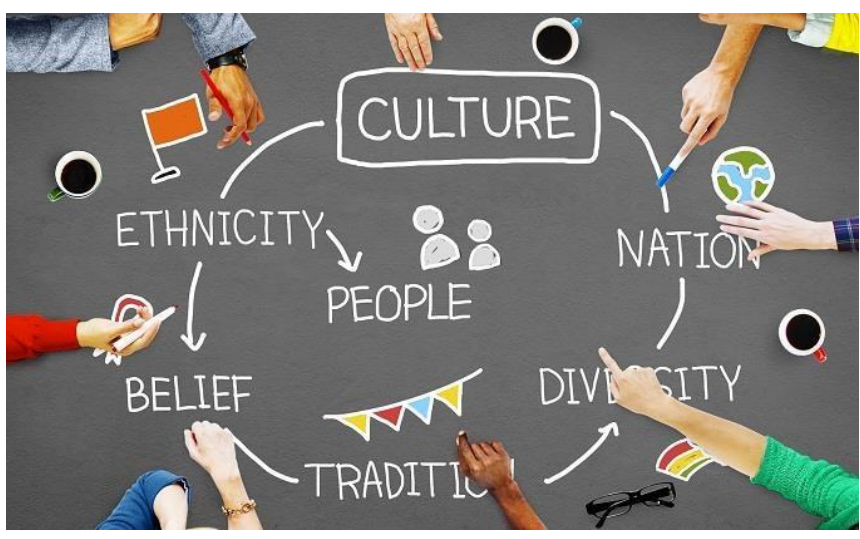

\section{TOURISM AUTHORITIES:}

The conscious move to protect the heritage product by the international community marks a double-edged sword for historic cities. The $20^{\text {th }}$ century marked a number of important milestones formally constituting the protection of cultural heritage by 


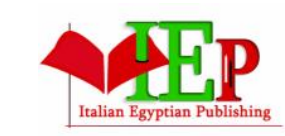

ISSN: $2735-4415$
INTERNATIONAL JOURNAL OF

MULTIDISCIPLINARY STUDIES IN ARCHITECTURE

AND CULTURAL HERITAGE

VOLUME 2, ISSUE 1, 2019, $54-66$.

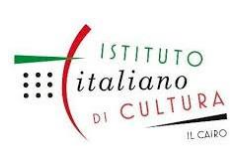

www.egyptfuture.org/ojs/

organizations such as UNESCO, ICCROM, ICOM and ICOMOS. The concept of cultural heritage has been broadened to include historic monuments and works of art in both urban and rural settings.

For particular importance, the 'World Heritage Convention' of 1972 outlined the need for the 'Protection of the World Cultural and Natural Heritage' by means of assessing whether cultural heritage sites were worthy to be inscribed on the UNESCO World Heritage List. And governments were obliged to adhere to the recommendations and guidelines in the Venice Charter related to different aspects of safeguarding cultural heritage. ${ }^{\mathrm{x}}$

As since 1972, a series of consecutive UNESCO conventions and declarations have aimed to set an international framework for the protection of diverse forms of heritage. While initially focusing on works of art, built environments and natural spaces (UNESCO 1970, 1972), later UNESCO conventions and declarations have included other forms of cultural heritage, notably the notion of intangible heritage. ${ }^{\mathrm{x}}$

Also since 1992, World Heritage Sites also include 'cultural landscapes' in recognition of the intimate relationships between culture and nature. ${ }^{\text {xii }}$ The 1972 UNESCO convention focused on the protection of the World Cultural and Natural Heritage, with an emphasis both on built environmentsand natural spaces, which are of 'outstanding universal value' from various aesthetic, scientific, artistic, and historic and conservationist points of view such as Historic Cairo \& Luxor. World Heritage Site status effectively allows greater levels of engagement with the past and its meanings outside of purely national, and sometimes, nationalistic contexts. ${ }^{\text {xiii }}$

Although the notion of 'cultural heritage' was originally conceived within the industrialized and developed world and thus reflected the works and values inherent in such societies, the idea hasbeen widened to cover heritages in the lesser developed world where there is less emphasis upon grand and permanent structures and recorded narratives. The recognition of intangible and 'movable' cultural heritage in the Convention for the Safeguarding for the Intangible Heritage (2003) significantly recognized other forms of heritage that has meaning beyond material manifestations, is transmitted through generations and which is also central in shaping identity. ${ }^{\text {xiv }}$

Recognizing the 'heritage of the world' not only signals a wider sense of responsibility towards our common past, but also the opportunities for public access to, education about, and the experience of, such important sites.

\section{HERITAGE AND IDENTITY:}

Heritage and identity are old concepts that are continuously revised, both academically and in social practice. Heritage can be envisaged as knowledge, simultaneously a cultural product and a political resource. In Livingstone's terms (1992), the nature of such knowledge is always negotiated, 


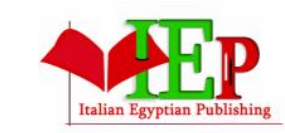

ISSN: $2735-4415$
INTERNATIONAL JOURNAL OF

MULTIDISCIPLINARY STUDIES IN ARCHITECTURE

AND CULTURAL HERITAGE

VOLUME 2, ISSUE 1, 2019, $54-66$.

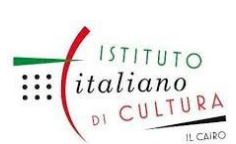

www.egyptfuture.org/ojs/

being set within specific social and intellectual circumstances. Heritage is the past after it has been packaged for certain uses.

Cultural heritage is critical to the identity of a community. In the context of the urban fabric, it cultural heritage may mean buildings that carry a significant meaning to locals, or those that provide a window to the past. While these buildings can present challenges in terms of achieving great environmental outcomes, reusing these assets has farreaching positive social impacts. The adaptive reuse of these buildings re-links them with the community, provides an avenue for improving the urban fabric, and can be a key element used to celebrate the history of the local area.

On the other hand, Identity is linked to 'senses of time' and atavistic fears in that it is not 'secured by a lifelong guarantee' and is 'eminently negotiable and revocable' (Bauman, 2004). The term refers to the ways in which markers such as: heritage; language; religion; ethnicity; nationalism; and shared interpretations of the past, are used to construct narratives of inclusion and exclusionthat define communities and the ways in which these latter are rendered specific and differentiated. ${ }^{\mathrm{xv}}$ Conceptual complexities has given both heritage and identity, the interrelationshipsbetween them are multi-faceted and both spatially and temporally variable.

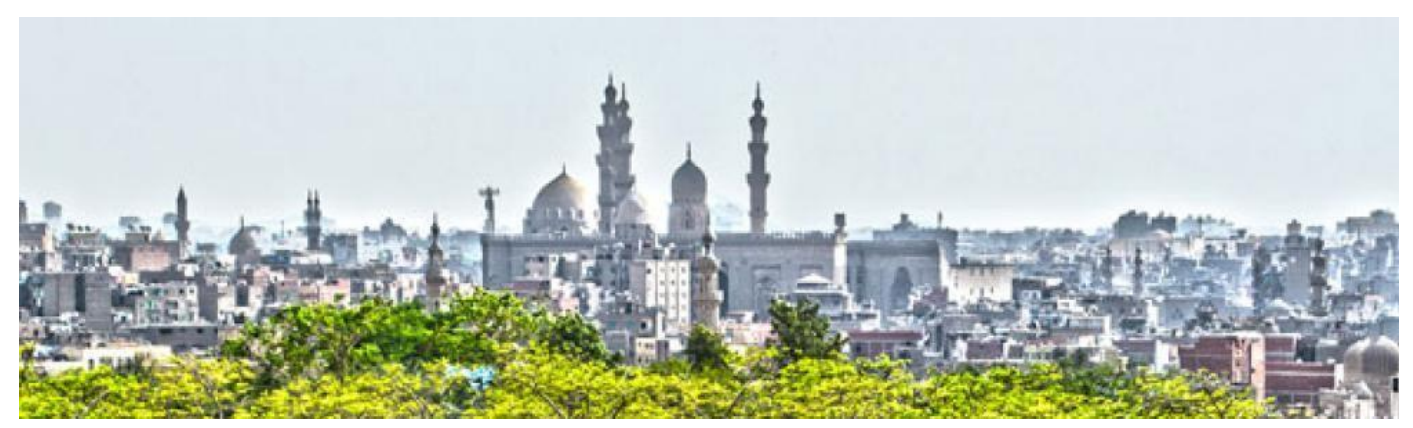

Figure (2): Historic Cairo

\section{TOURISM EXPRESSING CULTURE:}

There is a clear role for tourism in the process of expressing culture and cultural difference. In hisintervention at the Barcelona 2004 Universal Forum of Cultures, General Vice Director for Culture at the UNESCO, emphasized the role of tourism to enable spaces for "all cultures to express themselves and make themselves known, and hence to achieve a form of intercultural dialogue leading to peace and facilitating sustainable development". xvi

From a touristic perspective it is easy to see the value of historic buildings, heritage sites and objects d'art. Much of international tourism is centered on these material expressions of culture whether it is the Pyramids \& Historic Cairo in Egypt, the contents of the Louvre in Paris, France, or a city such as Venice in Italy.

In fact, the triangular "Tourism - Culture -Development" relationship has from the very outset leftits imprint on the emergence of tourism in developing countries. Indeed, when in the mid-1960s tourism made its appearance in southern destinations, it was 


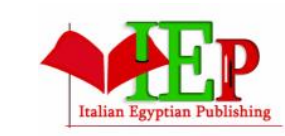

ISSN: $2735-4415$
INTERNATIONAL JOURNAL OF

MULTIDISCIPLINARY STUDIES IN ARCHITECTURE

AND CULTURAL HERITAGE

VOLUME 2, ISSUE 1, 2019, $54-66$.

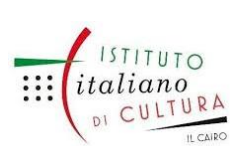

www.egyptfuture.org/ojs/

proposed as an economic activity that could help those countries emerge from their underdevelopment, hence the Tourism - Development relationship. ${ }^{\text {xvii }}$

Within this general framework, tourism is an economic sector that lends itself well to a process ofreflection which considers tourism within the cultural context of the host country. The participation of- people from the host country in the development of tourism is not solely limited to employment or the sale of goods and services; it also covers the cultural identity of these populations which forms the basis of their vision of the world.

\section{WORLD HERITAGE TOURISM:}

The very fact that such sites are recognized and designated for their universal significance can transform them very quickly into tourist destinations. Indeed, this is one reason why some countries seek inscription in the first place, along with reasons to do with genuine protection of sensitive sites, landscapes and species, and the increased international profile and prestige designation brings with it. World Heritage Site status effectively allows greater levels of engagement with the past and its meanings outside of purely national, and sometimes, nationalistic contexts. Sites are provided with global exposure which generates a discourse of both interest and tangible concern.

The designation of World Heritage Sites is not only a recognition of their significance, it is also a powerful means by which heritage can be liberated to a global audience. This increased exposure and popularity with tourists, can generate significant economic benefits for heritage sites and their wider geographical locations. At the same time it is important that such increased touristic activityis effectively managed to ensure the sustainability of the site and its surrounding communities. Increasingly, the World Heritage Centre, established in 1972 as the UNESCO coordinating body for World Heritage matters, is involved with management and training issues relating to the touristic dimension of sites, including supporting the elaboration of management plans to handle the pressures that tourists can create. ${ }^{\text {xiii }}$

Tourists do not only encounter cultural heritage as just 'the past', but rather the past of a particular people or community in a living context. Tourists engage with the cultural heritage of a destination not only through monumental forms but in more intangible ways as the past enshrined in contemporary behaviors and practices. Increasingly various forms of intangible heritage are being mobilized for tourism purposes and experiencing living heritage is a particularly enriching experience for both tourists and the community.

In short, tourism was a socio-economic activity engaging regional and local people. And there is potential through tourism for the reuse of redundant buildings for the tourism-related functions. Visitors have the benefit of a genuine setting, a local building is restored and community life enhanced. Tourism could both help to protect and enrich the cultural and natural heritage and, by taking into account the sociocultural effects on the local people, constitute a lasting economic resource.

\section{CASE STUDY: HISTORIC CAIRO:}




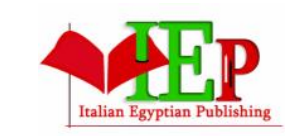

ISSN: $2735-4415$
INTERNATIONAL JOURNAL OF

MULTIDISCIPLINARY STUDIES IN ARCHITECTURE

AND CULTURAL HERITAGE

VOLUME 2, ISSUE 1, 2019, $54-66$.

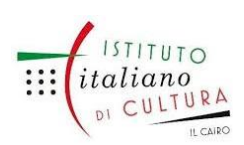

www.egyptfuture.org/ojs/

The wealth of the architectural heritage of Cairo needs no advertisement. It is best known for the monuments of the Pharaohs, The Coptic and Islamic periods also left highly interesting traces. In this respect, the site of the old city of Cairo, with its accumulation of historic and cultural heritage, is a veritable living museum, where Coptic churches and cathedrals stand side by side with Muslim mosques and citadels, all of which are major cultural tourist attractions.

The historic core of Cairo was internationally recognized as being of prime cultural significance only after its inscription in 1979. This event coincided with a politically motivated 'open-door' policy allowing for the first time, since the revolution of 1952, large numbers of foreign tourists to Egypt. As a result, package holidays to Egypt became readily available worldwide, luring tourists through a reinvention of the colonial past as depicted in tourist exhibits. ${ }^{\text {xix }}$

The integration between development goals and conservation aims established a complex interdependence between the various urban components (Nasser, 2002). In today's context, conservation and development are controlled by two separate bodies: the Supreme Council of Antiquities (SCA) (originally the Committee), and the Ministry of Planning. Partner to these authorities, the centralized Ministry of "Awqaf" still remains the largest landowner in the walled city. ${ }^{\mathrm{xx}}$ 


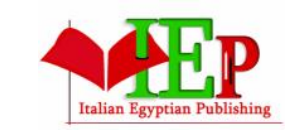

ISSN: 2735-4415

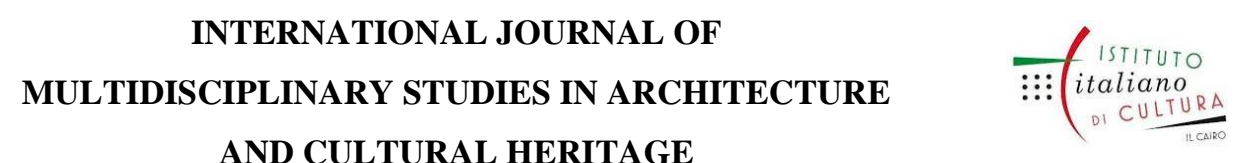

AND CULTURAL HERITAGE

VOLUME 2, ISSUE 1, 2019, 54-66.

www.egyptfuture.org/ojs/

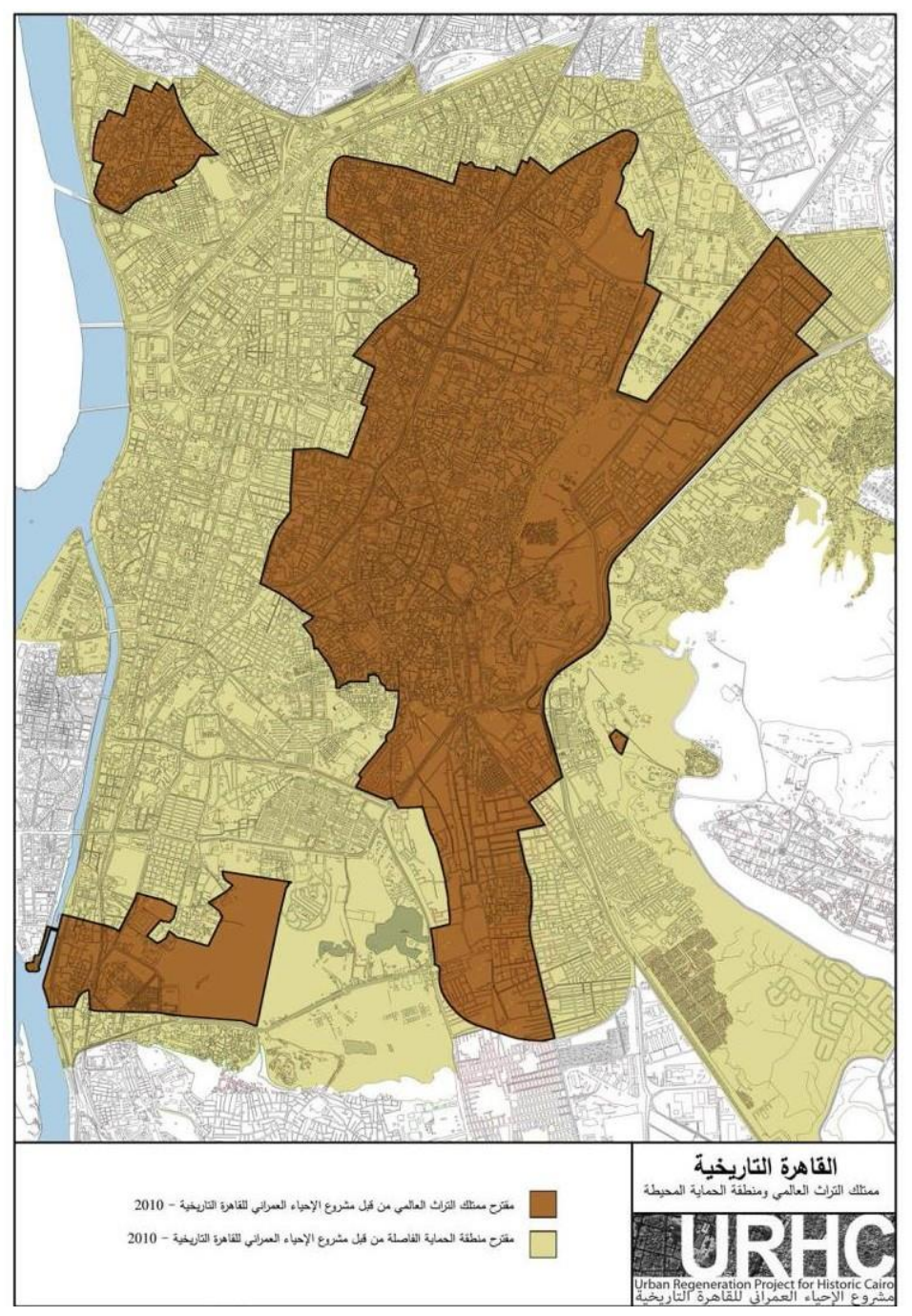

Figure (3): Boundaries of Historic Cairo

The beginnings of international tourism to Cairo followed Napoleon's expedition, which opened up the country and boosted research into the history and civilization of the Pharaohs. Without going so far back in time, it can be said that the interest shown in the heritage of ancient Egypt underpinned early tourist traffic, which was initially aristocratic, and in which cultural motives werecentral. Today, according to the WTO, the country receives more than $44 \%$ of the tourist traffic to Middle Eastern countries. More than with any other Arab country, the main motive behind tourist visits to Egypt remains cultural, with $23 \%$ of tourists coming solely to visit the architectural heritage.

The internal troubles which have primarily targeted Western tourists explain the dramatic fall in arrivals over recent years. The spatial dimension of tourism has only recently been seen as an essential part of policy development and the planning and management process. This is true of all tourist destinations, including tourist-historic 
cities, where tourist activities and the growing numberof tourists induce changes in urban form, in the physical structures, in the functional patterns and in the use of public space. Also, it has shown that different tourist activities have had a physical impact on the artifacts of the urban environment. Tourists visiting historical cities are attracted by the spatial concentration of historic buildings as a setting for sightseeing and the range of opportunities for related cultural activities.

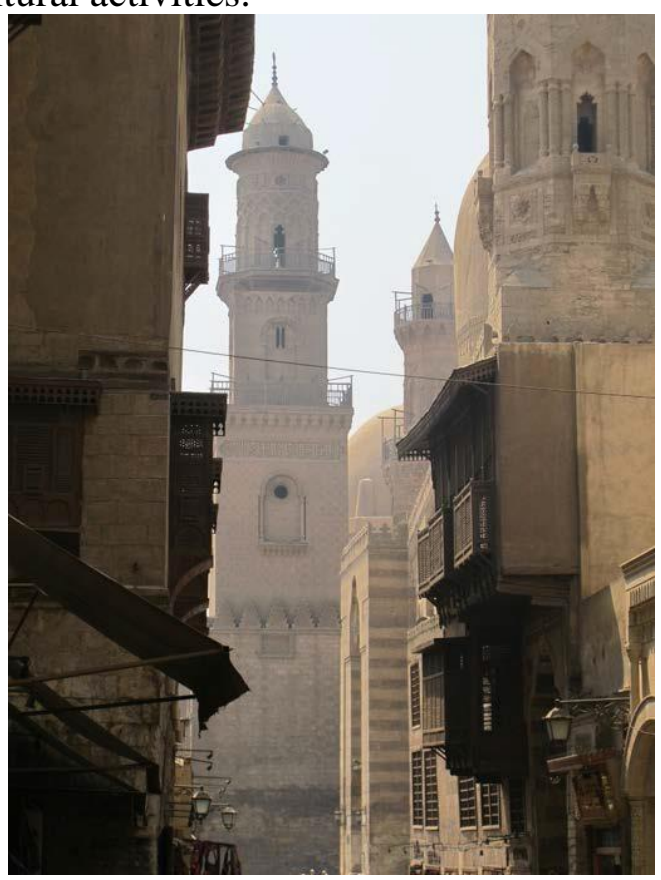

Figure (4): Al-Mu'izz Street, Katkudah, Beshtak.

Not just a physical heritage, but also a social and economic heritage that can still be seen today. The heritage is based on a complex relationship between social and physical planning. The urban elite were the keystone in this relationship, not just in their capacity as major urban landowners, but more importantly in their role as patrons of social welfare, which they exploited through the "Waqf system". Growth and contraction came in response to changes in Cairo's position in the global economy, markets were created, buildings adapted and residential buildings replaced by commercial land-uses, in the process changing Cairo's urban landscape. 
The commodification of tourism in Cairo showed that space was becoming segregated; tourism was claiming space for the consumers. These spaces tend to overlap with areas selected for the tourist activity based on a number of factors. First, state conservation and development policies are based on building selectivity. Second, the selection is also influenced by ease of accessibility to the main artery, al-Azhar Street.

Third, tourism has become the city's exclusive economy placing tremendous pressure on landowners, craftsmen and retailers to cater for the demand in tourism, thus leading to functional conversion.

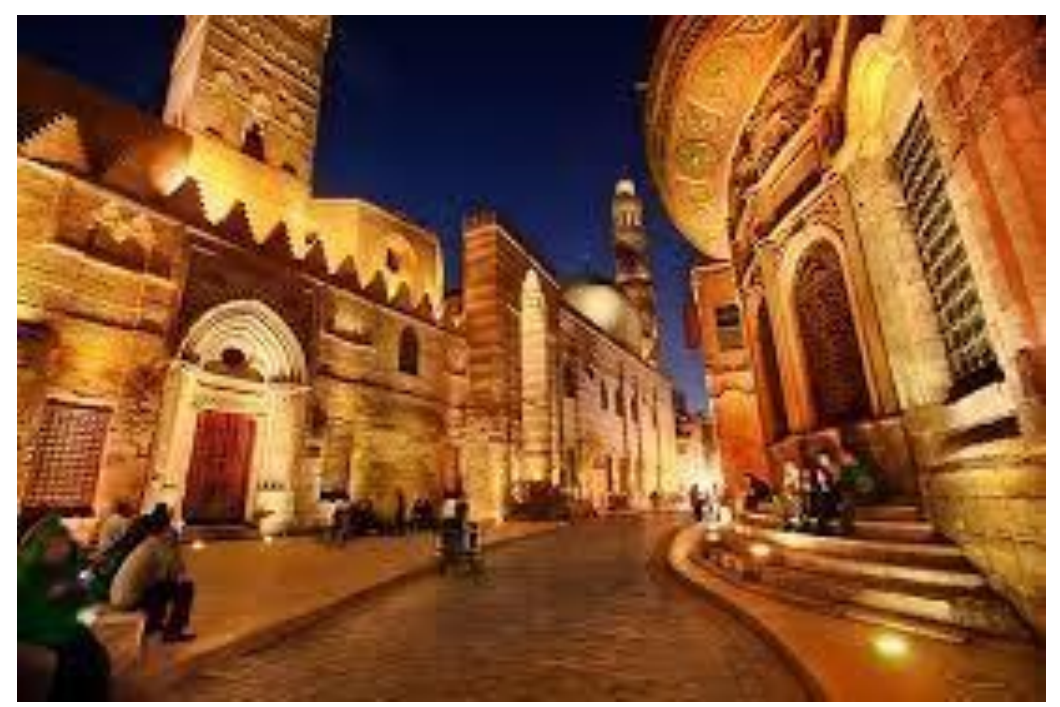

Figure (5): Al-Mu'izz Street, Sabil Al-Sultan.

\section{RESULTS:}

The symbiotic relationship between the physical, social and economic environment that Cairo enjoyed before the 19th century - has been disrupted by the way the tourist activity has fragmented these components. In this regard, tourism becomes an internalized and local activity, helping to sustain the social activities, cultural needs and the built heritage. Hence we could come out with a set of outcomes:

- Tourism has raised the economic potential for the walled city.

- Tourism may contribute to keep alive the cultural traditions and architectural identity. Their transformation into tourism resources enables the inhabitants of a zone to be aware of their heritage and carry it on and develop their area as well. At the same time, the tourism may create the motivation and means to preserve and improve the environment quality

- Cultural tourism shall speed up the territory planning, not only technically but 


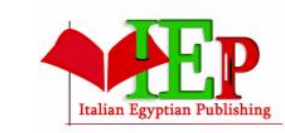

ISSN: $2735-4415$

INTERNATIONAL JOURNAL OF

MULTIDISCIPLINARY STUDIES IN ARCHITECTURE

AND CULTURAL HERITAGE

VOLUME 2, ISSUE 1, 2019, 54-66.

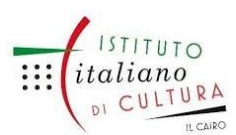

www.egyptfuture.org/ojs/

also aesthetically, with a positive effect on the locals' mood that is being more involved, active and productive.

- Increasing access to the culture becomes an active means of education the locals' information and cultural horizon, and of physical and psychical recovery of the local workforce, that is, one of the possible means of the labor productivity improvement.

- Tourism can provide the vehicle for urban regeneration and conservation, as cultural tourismbrings on the diversification of the opportunities and new facilities for leisure for the locals, as well as the stimulation of the residents to travel inside the country. As tourism development doesn't mean losing identity.

- There is a major role of the cultural tourism which is the recovery of some districts, zones, localities or towns.

- The properly planned cultural tourism have a major positive effect on the cultural resources and contributes to their maintenance and protection. By integrating the immovable cultural resources into the tourism circuit, financial resources may be collected for their conservationand development so that the future generations might enjoy them.

- Recycling revenues generated from viable activities such as those associated with tourism are not only dedicated to the conservation and rehabilitation of historic buildings, but also for the development of other community buildings and activities.

- Safeguarding the traditional urban texture through property laws, guidelines and the promotion of the robust building type characteristic of the area.

\section{RECOMMENDATIONS:}

Egypt has a chance not only to increase the development in cultural tourism, but also to support and emphasize its own heritage identity. Accordingly we may summarize a number of proposals as follows:

- Uniting the historic fabric with the rest of the walled city - Historic Cairo - to be consideredfor conservation and development.

- Responsible tourism marketing to ensure that the tourists are fully informed of theconsequences of their actions on the environment and local community.

- Application of the sustainable tourism principles in conjunction with conservation and rehabilitation of architectural heritage in Egypt. 


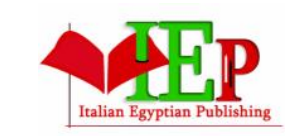

ISSN: $2735-4415$
INTERNATIONAL JOURNAL OF

MULTIDISCIPLINARY STUDIES IN ARCHITECTURE

AND CULTURAL HERITAGE

VOLUME 2, ISSUE 1, 2019, $54-66$.

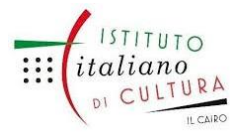

www.egyptfuture.org/ojs/

- Proper training and education of Locals to enable them to run a business and have a good chance for jobs in the area, and to involve in the tourism industry development.

- The stimulation of the enterprises working in the tourism and culture fields to use as many local products as possible in order to create and supply tourism and cultural products, but preventing the environmental troubles.

- Drawing-up of tourism projects based on the community, especially in the rural tourism field with cultural concerns.

- The historical districts are exposed to pollution and crowding due to the narrow streets that were not designed for today's traffic. The strategies for preventing the traffic jamming should include plans for car and pedestrian traffic.

- Continuous evaluation of the tourism impact on the environment. Planners should have a clear image of the particularly risky areas. The plans should allow for that tourism size that does not cause damage to the area. The impact of the tourism development in heritage sites could and must be controlled by adequate planning, development and management.

\section{REFERENCES:}

'Mike Robinson and David Picard, Culture, tourism and Development, UNESCO, p. 7, 2006.

ii Mike Robinson, Tourism encounters: Inter \& Intra-cultural conflicts \& the world's largest industry. TraditionalDwellings and Settlement Review X (1), 1998.

iii Mike Robinson and David Picard, Previous reference, UNESCO, p. 9, 2006.

iv OECD, Tourism and the Creative Economy, OECD Studies on Tourism, OECD Publishing, 2014.

vRichards, G. and Wilson, J., 'The Impact of Cultural Events on City Image: Rotterdam Cultural Capital ofEurope 2001', Urban Studies, 41(10): 1931-51, 2004.

viEuropean Travel Commission, World Tourism Organization, 2005.

vii Cultural Development, UNESCO, 2001.

viii Mike Robinson and David Picard, Previous reference, UNESCO, p. 17, 2006. 
INTERNATIONAL JOURNAL OF

MULTIDISCIPLINARY STUDIES IN ARCHITECTURE

AND CULTURAL HERITAGE

ix Rami Farouk Daher, Tourism in the Middle East_Continuity, Change And Transformation (Tourism andCultural Change), Multilingual Matters ,2006.

× Rami Farouk Daher, Previous reference, Multilingual Matters ,2006.

xi Cultural Heritage, UNESCO, 2003.

xii Mike Robinson and David Picard, Previous reference,

UNESCO, p. 22, 2006. xiii Mike Robinson and David Picard,

Previous reference, UNESCO, p. 29, 2006. ${ }^{\text {xiv }}$ Rami Farouk Daher,

Previous reference, Multilingual Matters ,2006.

xv Donald and Rattansi, Heritage \& Identity, 1992.

xvi Cultural Heritage, UNESCO, 2004.

xvii Derek Worthing, Stephen Bond, Managing built heritage (the role of cultural significance), John Wiley andSons, 2008.

xviii Cultural Heritage, UNESCO, 2001.

xix Gregory Derek, Colonial nostalgia and cultures of travel, London \& New York, Rutledge, 2001.

${ }^{x x}$ Rami Farouk Daher, Previous reference, Multilingual Matters ,2006.

Received: February 15, 2018

Accepted: April 20, 2018 